\title{
Production of $R$ - and S-1,2-propanediol in engineered Lactococcus lactis
}

\author{
Rintaro Sato ${ }^{1,2}$, Motoyuki Ikeda' ${ }^{1}$, Tomonari Tanaka ${ }^{1}$, Hitomi Ohara ${ }^{1}$ and Yuji Aso ${ }^{1,2^{*}}$ (D)
}

\begin{abstract}
1,2-propanediol (1,2-PDO) is a versatile chemical used in multiple manufacturing processes. To date, some engineered and non-engineered microbes, such as Escherichia coli, Lactobacillus buchneri, and Clostridium thermosaccharolyticum, have been used to produce 1,2-PDO. In this study, we demonstrated the production of $R$ - and S-1,2-PDO using engineered Lactococcus lactis. The L- and D-lactic acid-producing L. lactis strains NZ9000 and AH1 were transformed with the plasmid pNZ8048-ppy harboring pct, pduP, and yahK genes for 1,2-PDO biosynthesis, resulting in L. lactis LL1 and LL2, respectively. These engineered $L$. lactis produced $S$ - and $R-1,2-P D O$ at concentrations of 0.69 and $0.50 \mathrm{~g} / L$ with 94.4 and $78.0 \%$ ee optical purities, respectively, from $1 \%$ glucose after $72 \mathrm{~h}$ of cultivation. Both $1 \%$ mannitol and $1 \%$ gluconate were added instead of glucose to the culture of L. lactis LL1 to supply NADH and NADPH to the 1,2PDO production pathway, resulting in 75\% enhancement of S-1,2-PDO production. Production of S-1,2-PDO from 5\% mannitol and 5\% gluconate was demonstrated using L. lactis LL1 with a pH-stat approach. This resulted in S-1,2-PDO production at a concentration of $1.88 \mathrm{~g} / \mathrm{L}$ after $96 \mathrm{~h}$ of cultivation. To our knowledge, this is the first report on the production of $R$ - and S-1,2-PDO using engineered lactic acid bacteria.
\end{abstract}

Keywords: Bioproduction, Fermentation, Lactococcus lactis, 1,2-Propanediol

\section{Introduction}

Currently, sustainable manufacturing from biomass is in great demand to minimize negative environmental impacts (Abbasi and Abbasi 2010; Usmani et al. 2021). Bioproduction of a variety of industrial chemicals from biomass using microbes has been demonstrated (Tong et al. 1991; Huang et al. 2002, 2017; Nakamura and Whited 2003; Liang et al. 2011; Lin et al. 2016; Wang et al. 2017; Lee et al. 2018). For instance, Sato et al. demonstrated the direct production of 1,2-propanediol (1,2PDO) and 1,3-propanediol from starch using engineered Escherichia coli BW25113 (Sato et al. 2020) and showed that inactivation of $g l p F$ improves 1,3-propanediol production (Sato et al. 2021).

Among diols, 1,2-PDO is one of the most versatile chemicals with two optical isomers, $R-1,2-\mathrm{PDO}$ and

\footnotetext{
*Correspondence: aso@kit.ac.jp

1 Department of Biobased Materials Science, Kyoto Institute

of Technology, Kyoto, Japan

Full list of author information is available at the end of the article
}

S-1,2-PDO (Altras and Cameron 1999; Niu et al. 2019). These compounds can be produced from glucose and/or xylose or lactic acid by engineered and non-engineered microbes. Some lactic acid bacteria (LAB) such as Lactobacillus buchneri and Lactobacillus parabuchneri produce 1,2-PDO (Elferink et al. 2001; Krooneman et al. 2002). L. buchneri produces $0.6 \mathrm{~g} / \mathrm{L}$ of 1,2-PDO from $0.2 \%$ lactate (Elferink et al. 2001). Other researches demonstrated to produce the optical isomers of 1,2-PDO using microbes other than LAB (Cameron and Cooney 1986; Niu et al. 2019). For example, Clostridium thermosaccharolyticum HG-8 produced 3.8 and $3.2 \mathrm{~g} / \mathrm{L}$ of $R$-1,2-PDO from $3 \%$ glucose and 3\% xylose, respectively (Cameron and Cooney 1986). Engineered E. coli MG1655 possessing intrinsic or extrinsic lactate dehydrogenase (LDH) gene (ldhA or $l l d h)$, along with 1,2-PDO synthetic genes $p c t, p d u P$, and $y a h K$, which encode propionate CoA-transferase, aldehyde dehydrogenase, and alcohol dehydrogenase, respectively, produced $17.3 \mathrm{~g} / \mathrm{L}$ of $R-1,2-$ PDO and $9.3 \mathrm{~g} / \mathrm{L}$ of $S-1,2-\mathrm{PDO}$ from $4 \%$ glucose under
Springer Open

(c) The Author(s) 2021. This article is licensed under a Creative Commons Attribution 4.0 International License, which permits use, sharing, adaptation, distribution and reproduction in any medium or format, as long as you give appropriate credit to the original author(s) and the source, provide a link to the Creative Commons licence, and indicate if changes were made. The images or other third party material in this article are included in the article's Creative Commons licence, unless indicated otherwise in a credit line to the material. If material is not included in the article's Creative Commons licence and your intended use is not permitted by statutory regulation or exceeds the permitted use, you will need to obtain permission directly from the copyright holder. To view a copy of this licence, visit http://creativeco mmons.org/licenses/by/4.0/. 
fermenter-controlled cultivation conditions (Niu et al. 2019). 1,2-PDO can be produced in engineered microbes via a pathway in which glucose is first converted to $\mathrm{D}$ - and L-lactate, followed by the synthesis of $R$ - and $S$-1,2-PDO from D- and L-lactate, respectively, in which cofactors such as acetyl-CoA, NADH, and NADPH are required (Altras and Cameron 1999; Saxena et al. 2010; Niu and Guo 2015; Niu et al. 2019). This suggests that microbes producing the 1,2-PDO precursor lactate at a high titer are suitable as production hosts for 1,2-PDO production, and that $R$ - and $S-1,2-\mathrm{PDO}$ can be separately produced in $\mathrm{D}$ - and L-lactic acid producers, respectively. In fact, Niu et al. demonstrated the production of $R$ - and $S$-1,2-PDO separately using D- and L-lactic acid-producing engineered $E$. coli, respectively (Niu et al. 2019).

Based on their glycolytic metabolism, LAB can be classified into two groups: homo- and hetero-fermentative LAB (Axelsson 2004; Bintsis 2018). Homofermentative LAB, such as Lactococcus spp., theoretically yield $2 \mathrm{~mol}$ of lactate from $1 \mathrm{~mol}$ of consumed glucose. LAB can also be divided into three groups: $\mathrm{D}$-lactic acid producers, L-lactic acid producers, and both-isomer producers, which are determined by the catalytic properties of LDH encoded in their genomes (Gao et al. 2012; Rahman et al. 2013; Ghaffer et al. 2014; Eş et al. 2018). These results suggest that the use of homofermentative $\mathrm{LAB}$ as production hosts is reasonable for 1,2-PDO production, and that $\mathrm{D}$ - and L-lactic acid-producing LAB can be used to separate $R$ - and $S-1,2-\mathrm{PDO}$, respectively. Kuipers et al. constructed a recombinant host for the nisin-controlled gene expression (NICE) system, L. lactis NZ9000, by incorporating the two-component regulatory gene nisRK into the genome of L. lactis MG1363 (Kuipers et al. 1998). Since $L$. lactis NZ9000 has been used as a superior host for protein expression, this strain would be a suitable host for 1,2-PDO production. Recently, Aso et al. constructed a L. lactis NZ9000 derivative by replacing its major intrinsic L-LDH gene with a heterologous D-LDH gene from Lactobacillus delbrueckii subsp. lactis JCM 1107, resulting in a D-lactic acid producer, L. lactis AH1 (Aso et al. 2019). Using the AH1 strain, D-lactate was produced from starch directly by expression of a heterologous $\alpha$-amylase gene from Streptococcus bovis NRIC 1535. From this demonstration, it is presumed that $R$ and $S-1,2-\mathrm{PDO}$ can be produced by the expression of $p c t$, $p d u P$, and $y a h K$ in L. lactis NZ9000 and AH1, respectively, using the NICE system.

Therefore, the present study demonstrated the production of $R$ - and S-1,2-PDO using engineered L. lactis NZ9000 and AH1, respectively, through an exogenous 1,2-PDO production pathway, according to a previously reported demonstration using engineered E. coli (Niu et al. 2019) (Fig. 1). Additionally, it has been reported

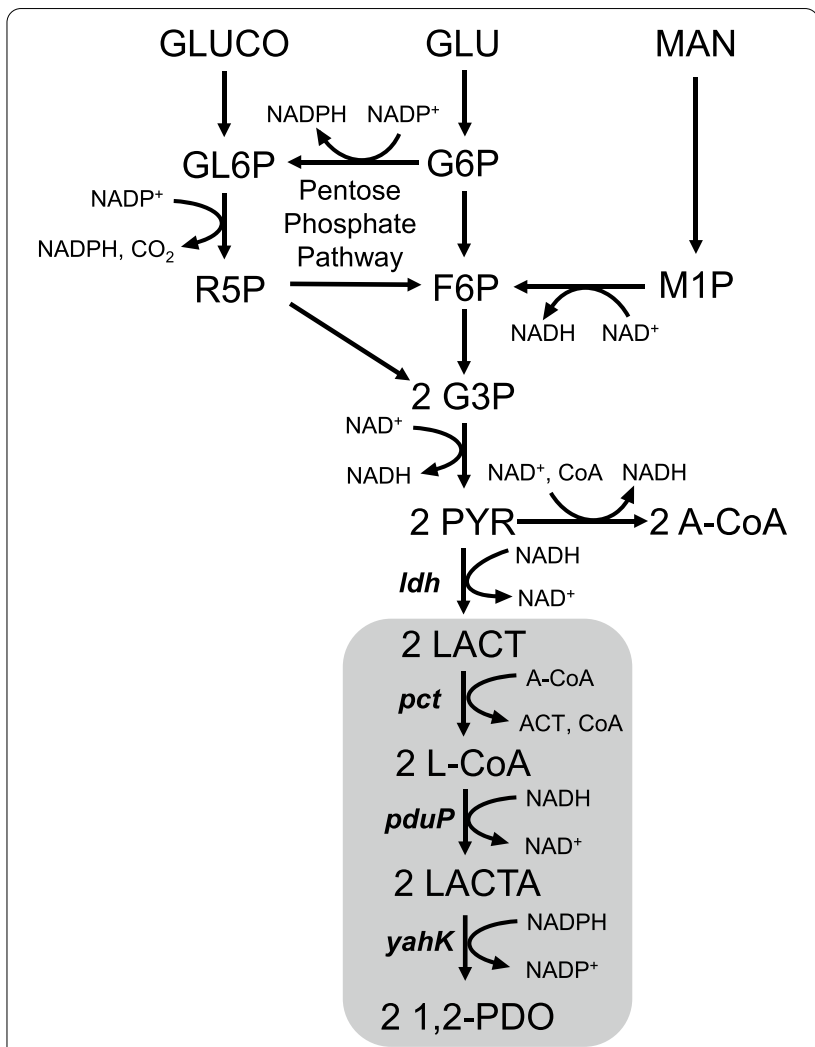

Fig. 1 Metabolic pathway of 1,2-PDO production in engineered L. lactis. 1,2-PDO, 1,2-propanediol; G6P, glucose 6-phosphate; F6P, fructose-6-phosphate; G3P, glyceraldehyde-3-phosphate; M1P, mannitol-1-phosphate; GL6P, gluconate-6-phosphate; R5P, ribose-5-phosphate; PYR, pyruvate; A-CoA, acetyl-coenzyme A; ACT, acetate; GLU, glucose, GLUCO, gluconate; MAN, mannitol; LACT, lactate; L-CoA, lactoyl-CoA; LACTA, lactaldehyde. Italicized letters indicate genes: Idh, lactate dehydrogenase gene; $p c t$, propionate CoA-transferase gene; $p d u P$, aldehyde dehydrogenase gene; yahK, alcohol dehydrogenase gene. The introduced pathway for 1,2-PDO production is colored in gray

that the metabolism of mannitol and gluconate in $L$. lactis results in enhancement of intracellular amounts of NADH and NADPH, respectively (Ramos et al. 2001; Neves et al. 2002; Wegmann et al. 2007; Linares et al. 2010). This suggests that addition of mannitol and gluconate improves 1,2-PDO production. To prove this, the effect of adding mannitol and gluconate to cultures of engineered L. lactis on 1,2-PDO production was investigated.

\section{Materials and methods}

Microorganisms and culture conditions

Lactococcus lactis NZ9000 (NIZO Food Research, Netherlands) (Kuipers et al. 1998) and AH1 (Aso et al. 2019) strains were grown in M17 medium (Difco Laboratories, MI, USA) supplemented with $0.5 \%$ glucose (GM17) 
at $30{ }^{\circ} \mathrm{C}$. Chloramphenicol was added to the cultures at a final concentration of $20 \mu \mathrm{g} / \mathrm{mL}$ when required. For 1,2-PDO production, recombinant $L$. lactis strains were grown at $30{ }^{\circ} \mathrm{C}$ and $150 \mathrm{rpm}$ under microaerobic conditions in M17 medium supplemented with 1\% glucose, $1 \%$ gluconate, and/or $1 \%$ mannitol. When gluconate and mannitol were added to the medium, $0.3 \mathrm{~g} / \mathrm{L}$ acetate was further added. In flask cultivation with $1 \%$ gluconate and $1 \%$ mannitol, an appropriate volume of $1 \mathrm{M} \mathrm{MOPS}(\mathrm{pH}$ 7.0) was added to the culture every $24 \mathrm{~h}$ to adjust the $\mathrm{pH}$ of the culture to 7.0. Microaerobic conditions were performed in $200 \mathrm{~mL}$ flasks filled with $133 \mathrm{~mL}$ medium and sealed with rubber stoppers. Nisin A (Sigma-Aldrich, MO, USA) was added to the cultures at a final concentration of $10 \mathrm{ng} / \mathrm{mL}$ to induce gene expression for 1,2PDO production when the optical density of cultures at $600 \mathrm{~nm}\left(\mathrm{OD}_{600}\right)$ reached 0.4-0.6.

To characterize production of L-lactate and S-1,2-PDO, resting cells of $L$. lactis LL1 were prepared as follows: recombinant $L$. lactis was cultivated in GM17 medium for $18 \mathrm{~h}$ at $30{ }^{\circ} \mathrm{C}$. After centrifugation of the culture for $10 \mathrm{~min}$, the culture supernatant was removed. Collected cells were resuspended in $1 \mathrm{~mL}$ of $100 \mathrm{mM}$ sodium phosphate buffer ( $\mathrm{pH} 7.0$ ) containing $1 \%$ glucose, $1 \%$ sodium gluconate, and/or 1\% mannitol after washing three times with distilled water. Resting cells were incubated for $72 \mathrm{~h}$ at $30^{\circ} \mathrm{C}$, and then the supernatant was subjected to analysis.

Fermentation controlled with a $\mathrm{pH}$-stat was performed in a $2 \mathrm{~L}$ jar fermenter M-1000B (Tokyo Rikakikai Co., Ltd., Tokyo, Japan) with a working volume of $1 \mathrm{~L}$ at an agitation speed of $80 \mathrm{rpm}$ at $30^{\circ} \mathrm{C}$ without aeration under microaerobic conditions, and the $\mathrm{pH}$ of the culture was maintained at 6.8 by automatic addition of $2 \mathrm{M} \mathrm{NaOH}$ using a peristaltic pump. The concentration of dissolved oxygen (DO) in the culture was monitored using a field controller, model mk-750 DO (Automatic System Research Co., Ltd., Saytama, Japan).

\section{Genetic engineering}

The plasmid pNZ8048-ppy for 1,2-PDO production was constructed as follows: a series of three genes, pct from Megasphaera elsdenii JCM 1772 (accession No. M26493), pduP from Salmonella enterica subsp. enterica NBRC 13245 (Accession No. AB680380), and yahK from E. coli BW25113 (Accession No. U00096), were amplified by PCR using the plasmid pSR5 (Sato et al. 2020) as a template with Q5 High-Fidelity DNA polymerase (New England Biolabs, MA, USA), and the primer set pct-F (5'-AATTATAAGGAGGCACTCACGAGGAGA TATACCATGAGAAAAGTAGAAATCATTAC-3') and yahK-R (5'-TACCGCATGCCTGCAGTACCTCAGTCT GTTAGTGTGCGATTATC-3'); the ribosome binding site (RBS) is underlined. The amplification reaction was as follows: denaturation at $98{ }^{\circ} \mathrm{C}$ for $2 \mathrm{~min}, 35$ cycles of denaturation at $98{ }^{\circ} \mathrm{C}$ for $10 \mathrm{~s}$, annealing at $60^{\circ} \mathrm{C}$ for $30 \mathrm{~s}$, and polymerization at $72{ }^{\circ} \mathrm{C}$ for $3 \mathrm{~min}$. The pNZ8048 vector (Kuipers et al. 1998) was amplified by PCR using the primer set pNZ8048-F (5'-AAAGCAATTACTGAT ATTGCTGAAAAATTG-3') and pNZ8048-R (5'-GGT GAGTGCCTCCTTATAATTTATTTTG-3') under the same conditions. The amplified fragments were ligated by Gibson assembly (Gibson et al. 2009) with Gibson Assembly Master Mix (New England Biolabs), resulting in pNZ8048-ppy. The $p c t, p d u P$, and $y a h K$ genes were cloned downstream of each RBS (Additional file 1). $L$. lactis NZ9000 and AH1, which were transformed with pNZ8048-ppy by electroporation according to a previously described protocol (Guchte et al. 1992), resulting in L. lactis LL1 and LL2, respectively.

\section{Analytical methods}

Concentrations of lactate, 1,2-PDO, glucose, gluconate, mannitol, acetate, and ethanol in the culture supernatants were measured using a Prominence HPLC system (Shimadzu, Kyoto, Japan) equipped with an Aminex HPX-87H (Bio-Rad, CA, USA) and a refractive index (RI) detector (Shimadzu). These analytes were eluted using a $5 \mathrm{mM}$ sulfuric acid solution at a flow rate of $0.4 \mathrm{~mL} /$ min at $30{ }^{\circ} \mathrm{C}$. The chirality of 1,2-PDO produced by $L$. lactis was determined using a Prominence HPLC system (Shimadzu) equipped with a CHIRAL ART Cellulose-C S-5 $\mu \mathrm{m}$ column (YMC Co., Ltd., Kyoto, Japan) and monitored using an RI detector (GL Science, Tokyo, Japan) according to a previously described protocol (Niu and Guo 2015). The mobile phase (99\% hexane and $1 \%$ isopropanol) was eluted at a flow rate of $0.5 \mathrm{~mL} / \mathrm{min}$ at $25{ }^{\circ} \mathrm{C}$. The chirality of lactate produced by $L$. lactis was analyzed using a Prominence HPLC system (Shimadzu) equipped with an MCI GEL CRS10W column (Mitsubishi Chemical, Tokyo, Japan) and monitored at $254 \mathrm{~nm}$ using $1 \mathrm{mM}$ copper (II) sulfate solution as the mobile phase at a $0.5 \mathrm{~mL} / \mathrm{min}$ flow rate (Aso et al., 2019). The specific growth rate $(\mu)$ was calculated as the slope of the regression line, from a plot between $\ln \left(\mathrm{X} / \mathrm{X}_{0}\right)$ and time $(\mathrm{t})$ during the exponential growth period, where $\mathrm{X}\left(\mathrm{OD}_{600}\right)$ and $\mathrm{X}_{0}\left(\mathrm{OD}_{600}\right)$ are the cell concentrations at $\mathrm{t}(\mathrm{h})$ and at the beginning of the exponential phase, respectively.

\section{Results}

\section{1,2-PDO production in engineered $L$. lactis}

Expression of proteins encoded by the $p c t, p d u P$, and yahK genes in engineered L. lactis was confirmed by SDS-PAGE analysis (data not shown). This showed that the NICE system induced expression of 1,2-PDO biosynthetic genes in engineered $L$. lactis. To check 1,2-PDO 
production in the engineered $L$. lactis, resting cells of $L$. lactis LL1 and LL2 were incubated for $72 \mathrm{~h}$ in a buffer containing $1 \%$ glucose (Table 1 ). After $72 \mathrm{~h}$ of incubation, L. lactis LL1 produced $0.62 \pm 0.00 \mathrm{~g} / \mathrm{L}$ of L-lactate and $0.69 \pm 0.01 \mathrm{~g} / \mathrm{L}$ of $S-1,2-\mathrm{PDO}$, and L. lactis LL2 produced $0.52 \pm 0.04 \mathrm{~g} / \mathrm{L}$ of D-lactate and $0.73 \pm 0.06 \mathrm{~g} / \mathrm{L}$ of $R-1,2-\mathrm{PDO}$. This showed that the introduced genes $p c t, p d u P$, and $y a h K$ function in both L. lactis NZ9000 and AH1. The optical purities of L-lactate and S-1,2PDO produced by L. lactis LL1 were $96.8 \%$ and $94.4 \%$ $e e$, respectively, and the optical purities of D-lactate and $R-1,2-$ PDO produced by $L$. lactis LL2 were $85.7 \%$ and $78.0 \% e e$, respectively. This showed that $R$-and $S-1,2-$ PDO can be separately produced in L. lactis LL1 and LL2, respectively.

For characterization of 1,2-PDO production, $L$. lactis LL1 and LL2 were cultivated for $72 \mathrm{~h}$ in M17 medium supplemented with $1 \%$ glucose in a flask. After $72 \mathrm{~h}$ of cultivation, L. lactis LL1 produced $0.33 \pm 0.00 \mathrm{~g} / \mathrm{L}$ of L-lactate and $0.69 \pm 0.01 \mathrm{~g} / \mathrm{L}$ of $S$-1,2-PDO. L. lactis LL2 produced $0.35 \pm 0.05 \mathrm{~g} / \mathrm{L}$ of D-lactate and $0.50 \pm$
$0.02 \mathrm{~g} / \mathrm{L}$ of $R-1,2-\mathrm{PDO}$ (Fig. 2). The production profiles were similar to those obtained using resting cells. The 1,2-PDO yield from glucose in L. lactis LL1 was 1.4 times as high as in L. lactis LL2 (Table 2). The specific growth rates $\mu$ of $L$. lactis LL1 and LL2 were $1.02 \pm 0.03 \mathrm{~h}^{-1}$ and $0.99 \pm 0.01 \mathrm{~h}^{-1}$, respectively. There was no significant difference between $\mathrm{OD}_{600}$ at $72 \mathrm{~h}$ of cultivation and $\mu$ of L. lactis LL1 and LL2 $(P>0.05)$, indicating that the production of the optical isomers did not affect cell growth. Acetate and ethanol were detected as the main by-products in the cultures, but these production levels were negligible compared to those of 1,2-PDO (Table 2).

\section{Supplementation of NADH and NADPH for 1,2-PDO production}

To investigate the effect of adding gluconate and mannitol on 1,2-PDO production, resting cells of L. lactis LL1 were incubated in a buffer supplemented with $1 \%$ glucose, $1 \%$ mannitol, and/or $1 \%$ gluconate. The production levels of L-lactate and $S$-1,2-PDO from $1 \%$ glucose were $0.66 \pm 0.01 \mathrm{~g} / \mathrm{L}$ and $0.69 \pm 0.01 \mathrm{~g} / \mathrm{L}$, respectively

Table 1 Production profiles of D- and L-lactate and R- and S-1,2-PDO in the engineered L. lactis after $72 \mathrm{~h}$ of incubation with $1 \%$ glucose

\begin{tabular}{|c|c|c|c|c|c|c|c|c|}
\hline \multirow[t]{2}{*}{ Strains } & \multicolumn{4}{|c|}{ Production $(g / L)$} & \multicolumn{4}{|c|}{ Optical purity (\% ee) } \\
\hline & D-lactate & L-lactate & $R-1,2-\mathrm{PDO}$ & S-1,2-PDO & D-lactate & L-lactate & $R-1,2-P D O$ & S-1,2-PDO \\
\hline L. lactis LL1 & $\begin{array}{c}0.01 \pm 0.00 \\
(0.1 \pm 0.01)^{\mathrm{a}}\end{array}$ & $\begin{array}{l}0.62 \pm 0.03 \\
(6.15 \pm 0.31)\end{array}$ & $\begin{array}{l}0.02 \pm 0.00 \\
(0.20 \pm 0.01)\end{array}$ & $\begin{array}{l}0.69 \pm 0.01 \\
(6.90 \pm 0.13)\end{array}$ & - & 96.8 & - & 94.4 \\
\hline L. lactis LL2 & $\begin{array}{c}0.52 \pm 0.03 \\
(5.20 \pm 0.01)\end{array}$ & $\begin{array}{c}0.04 \pm 0.01 \\
(0.40 \pm 0.05)\end{array}$ & $\begin{array}{c}0.73 \pm 0.04 \\
(7.30 \pm 0.04)\end{array}$ & $\begin{array}{c}0.09 \pm 0.01 \\
(0.90 \pm 0.14)\end{array}$ & 85.7 & - & 78.0 & - \\
\hline
\end{tabular}

${ }^{a}$ Yield (\%, g-product/g-glucose $\left.\times 100\right)$

(A)

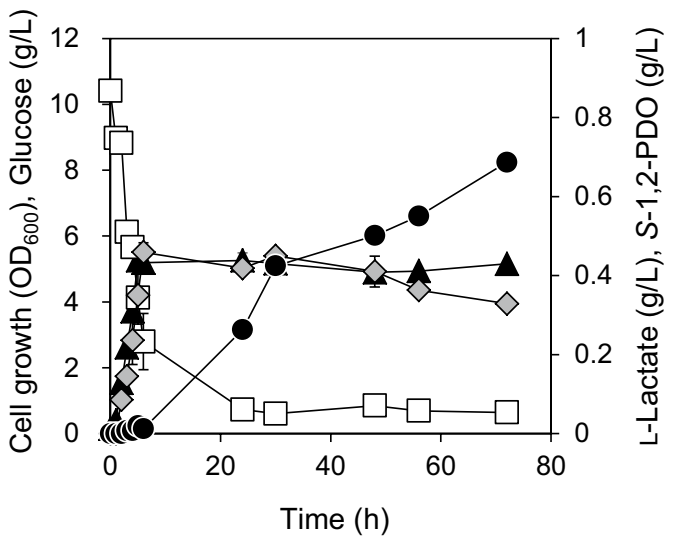

(B)

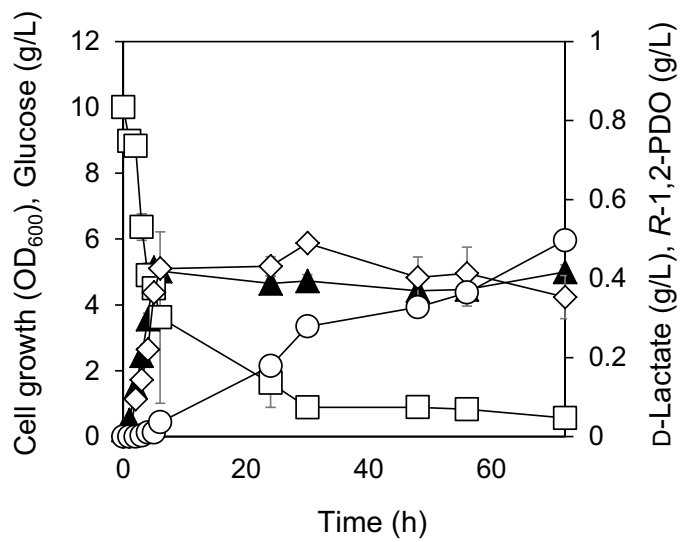

Fig. 2 Production of 1,2-PDO in A L. lactis LL1 and B LL2 with 1\% glucose in flask cultivation. The recombinants were cultivated in M17 medium supplemented with $1 \%$ glucose for $72 \mathrm{~h}$ under microaerobic conditions. Closed triangles, cell growth $\left(\mathrm{OD}_{600}\right)$; closed circles, S-1,2-PDO; shaded diamonds, L-lactate; open circles, R-1,2-PDO; open diamonds, D-lactate; open squares, glucose. This experiment was performed in duplicate, and the average is represented with error bars 
Table 2 Production profiles of metabolites in the engineered L. lactis after $72 \mathrm{~h}$ of cultivation with $1 \%$ glucose

\begin{tabular}{lllllll}
\hline Strains & $\mathbf{O D}_{600}$ & $\begin{array}{l}\text { Glucose } \\
\text { consumption } \\
(\mathbf{g} / \mathbf{L})\end{array}$ & $\mathbf{R - , ~ S - 1 , 2 - P D O}(\mathbf{g} / \mathbf{L})$ & $\mathbf{D}-$, L-lactate $(\mathbf{g} / \mathbf{L})$ & Acetate $(\mathbf{g} / \mathbf{L})$ & Ethanol (g/L) \\
\hline L. lactis LL1 & $5.16 \pm 0.06$ & $9.36 \pm 0.03$ & $0.69 \pm 0.00(6.90 \pm 0.01)^{\mathrm{a}}$ & $0.33 \pm 0.00(3.30 \pm 0.02)$ & $0.23 \pm 0.04(2.46 \pm 0.46)$ & $0.04 \pm 0.01(0.42 \pm 0.15)$ \\
L. lactis LL2 & $5.00 \pm 0.22$ & $9.43 \pm 0.09$ & $0.50 \pm 0.02(5.00 \pm 0.01)$ & $0.35 \pm 0.05(3.50 \pm 0.03)$ & $0.13 \pm 0.01(1.33 \pm 0.13)$ & $0.03 \pm 0.02(0.32 \pm 0.15)$ \\
\hline
\end{tabular}

${ }^{a}$ Yield $(\%$, g/g-glucose $\times 100)$

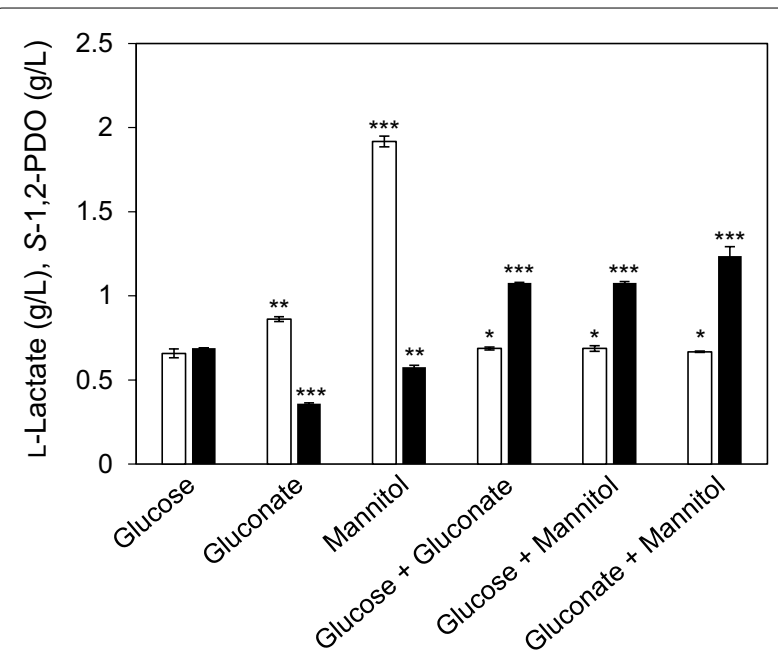

Fig. 3 Characterization of S-1,2-PDO and L-lactate production in the resting cells of $L$. lactis $L L 1$ incubated with $1 \%$ glucose, $1 \%$ mannitol, and/or $1 \%$ gluconate. The resting cells of L. lactis LL1 were incubated for $72 \mathrm{~h}$ at $30^{\circ} \mathrm{C}$ in $100 \mathrm{mM}$ phosphate buffer containing $1 \%$ glucose, $1 \%$ mannitol, and/or $1 \%$ gluconate. White bars, L-lactate; black bars, S-1,2-PDO. This experiment was performed in duplicate, and the average is represented with error bars. ${ }^{*} P>0.05,{ }^{*} 0.01<P<0.05$, ${ }^{* *} P<0.01$ vs addition of only $1 \%$ glucose
(Fig. 3). Interestingly, adding $1 \%$ gluconate significantly improved L-lactate production $(0.80 \pm 0.01 \mathrm{~g} / \mathrm{L})$, but $S$-1,2-PDO production was largely the same as when only glucose was added $(0.58 \pm 0.01 \mathrm{~g} / \mathrm{L})$. Addition of $1 \%$ mannitol alone led to the lowest $S$-1,2-PDO production $(0.36 \pm 0.01 \mathrm{~g} / \mathrm{L})$. On the other hand, addition of $1 \%$ mannitol or $1 \%$ gluconate with $1 \%$ glucose improved $S$-1,2-PDO production $(1.08 \pm 0.01 \mathrm{~g} / \mathrm{L}$ and $1.08 \pm$ $0.02 \mathrm{~g} / \mathrm{L}$, respectively). The highest production of $S-1,2-$ PDO was obtained when both $1 \%$ mannitol and $1 \%$ gluconate without glucose were added $(1.24 \pm 0.01 \mathrm{~g} / \mathrm{L})$. These results indicate that NADH and NADPH were supplied through the metabolism of mannitol and gluconate, and consequently, 1,2-PDO production was improved.

To characterize $S$-1,2-PDO production with gluconate and mannitol, L. lactis LL1 was cultivated with $1 \%$ mannitol and $1 \%$ gluconate for $72 \mathrm{~h}$ in a flask. The medium was supplemented with $0.3 \mathrm{~g} / \mathrm{L}$ of acetate to enhance the intracellular level of acetyl-CoA in L. lactis

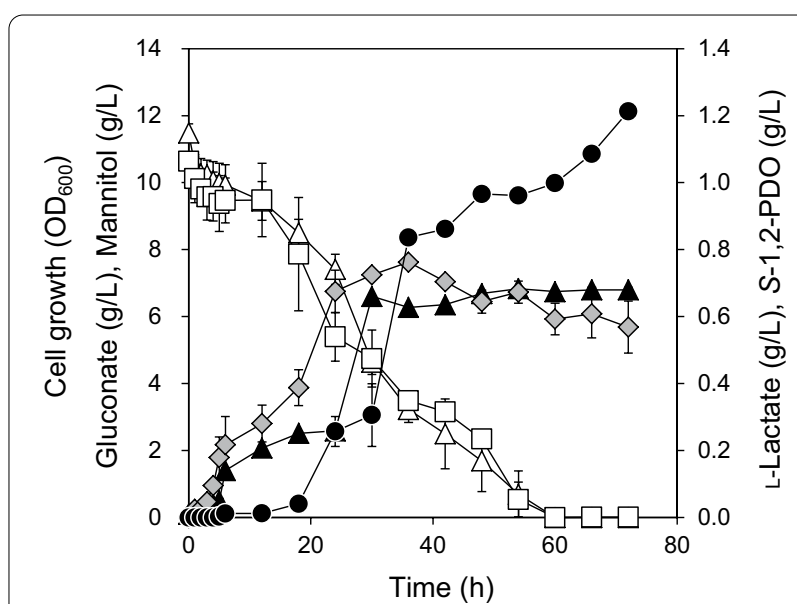

Fig. 4 Production of 1,2-PDO in L. lactis LL1 with 1\% gluconate and $1 \%$ mannitol in flask cultivation. L. lactis LL1 was cultivated for $72 \mathrm{~h}$ at $30^{\circ} \mathrm{C}$ in $\mathrm{M} 17$ medium supplemented with $1 \%$ mannitol and $1 \%$ gluconate under microaerobic conditions. The medium was supplemented with $0.3 \mathrm{~g} / \mathrm{L}$ acetate. The initial $\mathrm{pH}$ of the culture was 7.0. The culture was supplemented with 1 M MOPS (pH 7.0) every $24 \mathrm{~h}$ so that the $\mathrm{pH}$ of the culture was readjusted to 7.0. Closed triangles, cell growth $\left(\mathrm{OD}_{600}\right)$; closed circles, S-1,2-PDO; shaded diamonds, L-lactate; open triangles, mannitol; open squares, gluconate. This experiment was performed in duplicate, and the average is represented with error bars

(Puvendran and Jayaraman 2019). The initial $\mathrm{pH}$ of the culture was 7.0, but at $24 \mathrm{~h}$ of cultivation was 6.3. This was caused by L-lactate production, and resulted in $3.0 \mathrm{~g} / \mathrm{L}$ of mannitol and $4.6 \mathrm{~g} / \mathrm{L}$ of gluconate remaining in culture after cultivation. To promote consumption of mannitol and gluconate by L. lactis LL1, the $\mathrm{pH}$ of the culture was adjusted to 7.0 every $24 \mathrm{~h}$ by adding $1 \mathrm{M}$ MOPS (pH 7.0). After $72 \mathrm{~h}$ of cultivation, L. lactis $\mathrm{LL} 1$ produced $0.57 \pm 0.08 \mathrm{~g} / \mathrm{L}$ of L-lactate and $1.21 \pm$ $0.01 \mathrm{~g} / \mathrm{L}$ of $S-1,2-$ PDO from $1 \%$ mannitol and $1 \%$ gluconate (Fig. 4). The production titers of L-lactate and $S$-1,2-PDO were 1.7 times as high as those obtained with $1 \%$ glucose. The $\mathrm{OD}_{600}$ after $30 \mathrm{~h}$ of cultivation was $6.61 \pm 0.06$, and $\mu$ was $0.24 \pm 0.00 \mathrm{~h}^{-1}$. These properties were comparable to those observed when cells were cultured with $1 \%$ glucose. This indicates that supplementation with mannitol and gluconate had similar effects on cell growth. Consumption rates of gluconate 
and mannitol were similar (gluconate, $0.19 \mathrm{~g} / \mathrm{L} / \mathrm{h}$; mannitol, $0.18 \mathrm{~g} / \mathrm{L} / \mathrm{h})$.

It is known that maintaining the $\mathrm{pH}$ of L. lactis culture using a $\mathrm{pH}$-stat method improves lactate production because a decrease in $\mathrm{pH}$ represses cell growth (Carvaiho et al. 2013). Therefore, we performed $\mathrm{pH}-$ stat-controlled production of $S-1,2-\mathrm{PDO}$ in M17 medium supplemented with $5 \%$ mannitol and $5 \%$ gluconate in a jar-fermenter. The medium was supplemented with $0.3 \mathrm{~g} / \mathrm{L}$ acetate. Concentrations of the carbon sources were changed from 1 to $5 \%$ for prolonged cultivation because these compounds were depleted within $24 \mathrm{~h}$ of cultivation when $1 \%$ mannitol and $1 \%$ gluconate were used (data not shown). The $\mathrm{pH}$ of the culture was maintained near 6.8 during cultivation by the addition of $4 \mathrm{M} \mathrm{NaOH}$ (Fig. 5). The concentration of DO in the culture gradually decreased to $10.4 \%$ after $12 \mathrm{~h}$ of cultivation, and then remained almost constant after $48 \mathrm{~h}$ of cultivation (54.7-63.7\%). L. lactis LL1 produced L-lactate $(6.87 \pm 1.13 \mathrm{~g} / \mathrm{L})$ and $S-1,2-\mathrm{PDO}(1.88 \pm 0.44 \mathrm{~g} / \mathrm{L})$ after $96 \mathrm{~h}$ of cultivation. The $\mathrm{OD}_{600}$ after $48 \mathrm{~h}$ of cultivation was $6.72 \pm 0.86$, and $\mu$ was $0.15 \pm 0.02 \mathrm{~h}^{-1}$. Compared to results obtained in flask cultivation, the production titers of L-lactate and S-1,2-PDO were 11.9 and 0.6 times higher, respectively. Gluconate was consumed first, and the consumption rate of gluconate was 1.8 times as high as that of mannitol during $54 \mathrm{~h}$ of cultivation.

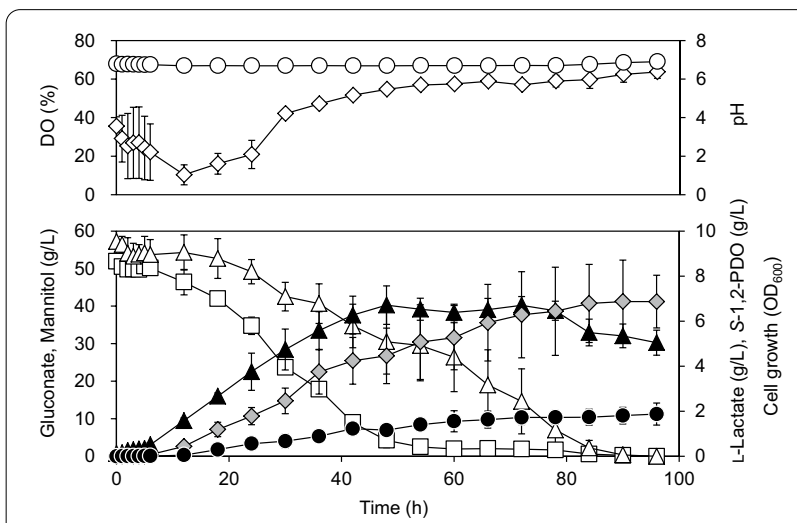

Fig. 5 Production of 1,2-PDO in L. lactis LL1 from 5\% mannitol and $5 \%$ gluconate in a jar fermenter controlled with a $\mathrm{pH}-$ stat. L. lactis LL1 was cultivated for $96 \mathrm{~h}$ at $30^{\circ} \mathrm{C}$ in M17 medium supplemented with $5 \%$ mannitol and $5 \%$ gluconate under microaerobic conditions. The medium was supplemented with $0.3 \mathrm{~g} / \mathrm{L}$ acetate. The $\mathrm{pH}$ of the culture was maintained at 6.8 by addition of $2 \mathrm{M} \mathrm{NaOH}$ during cultivation. Closed triangles, cell growth $\left(\mathrm{OD}_{600}\right)$; closed circles, S-1,2-PDO; shaded diamonds, L-lactate; open triangles, mannitol; open squares, gluconate; open diamonds, concentration of DO in the culture; open circles, $\mathrm{pH}$ of the culture. This experiment was performed in duplicate, and the average is represented with error bars

\section{Discussion}

Since the biosynthetic pathway for the production of 1,2-PDO has been reported, bioproduction of this compound has been attempted by introducing the biosynthetic pathway in various microorganisms including E. coli (Cameron and Cooney 1986, Niu and Guo 2015, Niu et al. 2019). In this study, we demonstrated production of $R$ - and $S-1,2-\mathrm{PDO}$ using engineered $L$. lactis constructed from $\mathrm{L}$ - and D-lactic acid-producing LAB, $L$. lactis NZ9000, and AH1, respectively, by expression of 1,2-PDO biosynthetic genes with glucose, mannitol, and/ or gluconate (Fig. 1). The advantage of using LAB is that lactic acid is the main organic acid required for $L A B$ to produce the desired product, 1,2-PDO.

The resting cells of $L$. lactis LL1 produced L-lactate and $S-1,2-\mathrm{PDO}$ at concentrations of $0.62 \mathrm{~g} / \mathrm{L}$ and $0.69 \mathrm{~g} / \mathrm{L}$, respectively, with negligible production of other isomers (Table 1). On the other hand, L. lactis LL2 produced an isomer each of lactate and 1,2-PDO (Table 1). This is because $L$. lactis AH1, which is the parent strain of $L$. lactis LL2, has been reported to produce D-lactate at an optical purity of $87.5 \%$ ee (Aso et al. 2019). We obtained a similar result, in that the optical purity of D-lactate was $85.7 \%$ ee when L. lactis LL2 was cultivated in this study. These results indicate that the optical purities of $R$ - and $S$-1,2-PDO produced by the engineered $L$. lactis were determined in accordance with those of the $\mathrm{D}$ - and L-lactate produced. The low D-lactate optical purity of L. lactis LL2 is due to the fact that L. lactis AH1 has lldh homologue genes $(l d h \mathrm{~B}, l d h \mathrm{X}$, and $h i c \mathrm{D})$ in addition to $l l d h$ (Aso et al. 2019). The production of lactate, a primary metabolite, is known to be associated with cell growth. Actually, however, the resting cells of L. lactis LL1 and LL2 produced lactate and 1,2-PDO from glucose. This is may be due to that L. lactis MG1363, which is the parent strain of L. lactis LL1 and LL2, maintains enzymatic activity related to the glycolysis during all phases of cell growth (Palmfeldt et al. 2004). ATP was probably pooled in the resting cells. Because, it has been reported that ATP in the resting cells of L. lactis was increased compared to the growing cells (Palmfeldt et al. 2004).

Production of $R$ - and $S-1,2-\mathrm{PDO}$ in the growing cells of L. lactis LL1 and LL2 with $1 \%$ glucose at $72 \mathrm{~h}$ of cultivation was characterized. Production of 1,2-PDO by $L$. lactis LL1 was 1.4 times as high as that produced by $L$. lactis LL2 (Fig. 2). Interestingly, production of 1,2-PDO by L. lactis LL1 was more than 40 times as high as that produced by a pflA-deficient E. coli BW25113, harboring the same set of 1,2-PDO biosynthetic genes, from $1 \%$ glucose, as previously reported (Sato et al. 2020). The engineered $E$. coli produced heterofermentatively D-lactate along with acetate and ethanol at non-negligible concentrations, leading to the decrease of the yield 
of D-lactate. On the other hand, engineered $E$. coli that produced the maximum 1,2-PDO titer, showed $1.05 \mathrm{~g} / \mathrm{L}$ acetate, and $0.13 \mathrm{~g} / \mathrm{L}$ ethanol production from $1 \%$ glucose (Niu et al. 2019). In contrast, homofermentative LAB, including $L$. lactis, produce lactate with by-products at negligible concentrations. Therefore, 1,2-PDO production by engineered L. lactis significantly increased compared to that produced by the engineered the engineered pflA-deficient E. coli BW25113. L. lactis effectively produces lactate from glucose under microaerobic conditions (Papagianni et al. 2007). L. lactis is cultured under aerobic conditions, the lactate production is low due to NADH oxidase. This results in the production of acetate (Neves et al. 2002). On the other hand, 1 mol each of acetyl-CoA, NADH, and NADPH are required for $1 \mathrm{~mol}$ of 1,2-PDO production. To supply acetyl-CoA, microaerobic conditions were demonstrated in this study. Although this study demonstrated to produce 1,2-PDO under microaerobic condition, the lactate titer of L. lactis LL1 and LL2 was lower than that of L. lactis NZ9000 and AH1 which produced $7.0 \mathrm{~g} / \mathrm{L}$ and $6.6 \mathrm{~g} / \mathrm{L}$ of lactate from $1 \%$ glucose, respectively (Aso et al. 2019). This result indicated that the overexpression of $p c t, p d u P$, and $y a h K$ induced the conversion of lactate to 1,2-PDO. Overexpression of phosphofructokinasegene ( $p f k A)$ from Aspergillus niger in L. lactis LM0230 improved glucose uptake and enhanced lactate production yields (Papagianni and Avramidis 2011). Therefore, the overexpression of $p f k A$ gene in L. lactis LL1 and LL2 might be improved lactate and 1,2-PDO productions.

It is known that additional NADH and NADPH are generated in L. lactis through the metabolism of gluconate and mannitol, and that mannitol-1-phosphate dehydrogenase and 6-phospogluconate dehydrogenase generate NADH and NADPH, respectively (Ramos et al. 2001; Neves et al. 2002; Wegmann et al. 2007; Linares et al. 2010; Zhao et al., 2017). To improve 1,2-PDO production by supplying these cofactors to the 1,2-PDO biosynthetic pathway, effects of adding glucose, mannitol, and/or gluconate on 1,2-PDO and lactate production using the resting cells of L. lactis LL1 were investigated. Although addition of either $1 \%$ mannitol or gluconate led to decreased $S$-1,2-PDO production compared to addition of $1 \%$ glucose, addition of both compounds resulted in the highest S-1,2-PDO production (Fig. 3). Mannitol is intracellularly converted to mannitol-1-phosphate, followed by the formation of fructose-6-phosphate. Fructose-6-phosphate is not metabolized via the pentose phosphate pathway, in which NADPH is generated. Therefore, the addition of $1 \%$ mannitol alone led to the lowest $S$-1,2-PDO production. It was suggested that the addition of gluconate alone does not contribute to the cellular redox balance and consequently results in a decrease in $S-1,2-\mathrm{PDO}$ production. Interestingly, the production of L-lactate was significantly enhanced by the addition of $1 \%$ gluconate. This may be because sodium ions derived from gluconate neutralize the L-lactate produced, and then the resting cells produce a large amount of L-lactate $(1.92 \mathrm{~g} / \mathrm{L})$.

Production of S-1,2-PDO was characterized by cultivation of L. lactis LL1 with M17 medium supplemented with $1 \%$ gluconate and $1 \%$ mannitol in flask cultivation. The use of $1 \%$ gluconate and $1 \%$ mannitol led to $75 \%$ enhancement of $S-1,2-\mathrm{PDO}$ production than did the use of $1 \%$ glucose (Fig. 4). In the metabolic pathway in the engineered L. lactis, $1 \mathrm{~mol}$ of NADH are synthesized from $1 \mathrm{~mol}$ of mannitol whereas $1 \mathrm{~mol}$ of $\mathrm{NADH}$ and $1 \mathrm{~mol}$ of NADPH are synthesized from $1 \mathrm{~mol}$ of gluconate (Niu et al. 2019) (Fig. 1). In the following step, the synthetic pathway for 1,2-PDO production consumes the equivalent numbers of NADH and NADPH. This ensures the redox balance for the whole process. This proves that 1,2-PDO production is enhanced by an additional supply of NADH and NADPH derived from mannitol and gluconate in the engineered L. lactis. Niu and Guo have also mentioned the necessity of supplying NADH and NADPH for 1,2-PDO production in recombinant $E$. coli (Niu and Guo 2015; Niu et al. 2019).

Generally, lactate production by LAB can be improved by maintaining the $\mathrm{pH}$ of the cultures during fermentation (Andersen et al., 2009; Carvaiho et al. 2013). Therefore, jar fermenter cultivation with a $\mathrm{pH}-$ stat for $S$-1,2-PDO production was performed with $5 \%$ gluconate and $5 \%$ mannitol. As a result, the production of lactate was improved, but the production of 1,2-PDO did not significantly increase (Fig. 5). In flask cultivation with $1 \%$ mannitol and $1 \%$ gluconate, there is no significant difference between the consumption rates of gluconate and mannitol (gluconate, $0.19 \mathrm{~g} / \mathrm{L} / \mathrm{h}$; mannitol, $0.18 \mathrm{~g} / \mathrm{L} / \mathrm{h}$ ). However, the consumption rate of gluconate was 1.8 times as high as that of mannitol in the jar-fermenter cultivation with $5 \%$ mannitol and $5 \%$ gluconate during $54 \mathrm{~h}$ of cultivation (gluconate, $0.91 \mathrm{~g} / \mathrm{L} / \mathrm{h}$; mannitol, $0.51 \mathrm{~g} / \mathrm{L} / \mathrm{h}$ ). Neves et al. reported that the NADH burden caused by mannitol-1-phosphate dehydrogenase inhibits mannitol metabolism in L. lactis MG1363 cultivated with mannitol (Neves et al. 2002). On the other hand, gluconate seems to be metabolized through the pentose phosphate pathway and glycolysis without such obstruction because NADPH generated from gluconate is smoothly consumed for the synthesis of cell biomass, especially during the exponential growth phase. This suggests that gluconate is more easily metabolized than mannitol when added at a higher concentration (5\%), and consequently, gluconate is consumed first. The production rate of $S-1,2-$ PDO was nearly constant after $48 \mathrm{~h}$ of cultivation. This 
may be because gluconate in the culture was almost completely consumed after $48 \mathrm{~h}$ of cultivation. Instead of the addition of gluconate, overexpression of fructose 1,6-bisphosphatase gene $(f b p)$ and glucose-6-phosphate dehydrogenase gene $(z w f)$ for NADPH supply might be possible.

\section{Supplementary Information}

The online version contains supplementary material available at https://doi. org/10.1186/s13568-021-01276-8.

Additional file 1: The partial sequence of pNZ8048-ppy.

\section{Acknowledgements}

We thank the NIZO Food Research (Netherlands), the National BioResource Project (National Institute of Genetics, Japan), the Biological Resource Center (NITE, Japan), the National Collection of Industrial, the Japan Collection of Microorganisms (RIKEN BioResource Research Center, Japan) for providing us with L. lactis NZ9000 and pNZ8048, E. coli BW25113, S. enterica subsp. enterica NBRC 13245, and M. elsdenii JCM 1772, respectively.

\section{Authors' contributions}

Substantial contribution to conception and design or the acquisition and analysis of data: RS, MI, YA. Drafting or critically revising the manuscript: RS, TT, $\mathrm{HO}$, YA. Approval of the final submitted version: RS, MI, TT, HO, YA. All authors read and approved the final manuscript.

\section{Funding}

This work was supported by Japan Science and Technology Agency-Mirai R\&D Program Grant Number JPMJMI17EC.

\section{Availability of data and materials}

The authors can confirm that all relevant data are included in the article.

\section{Declarations}

\section{Ethics approval and consent to participate}

This article does not any studies with human participants or animals performed by any of the authors.

\section{Consent for publication}

Not applicable.

\section{Competing interests}

The authors declare no competing interests associated with this article.

\section{Author details}

${ }^{1}$ Department of Biobased Materials Science, Kyoto Institute of Technology, Kyoto, Japan. ${ }^{2}$ JST-Mirai Program, Japan Science and Technology Agency, Saitama, Japan.

Received: 3 August 2021 Accepted: 6 August 2021 Published online: 16 August 2021

\section{References}

Abbasi T, Abbasi SA (2010) Biomass energy and the environmental impacts associated with its production and utilization. Renew Sustain Energy Rev 14:919-937

Altras EN, Cameron CD (1999) Metabolic of a 1,2-propanediol pathway in Escherichia coli. Appl Environ Microbiol 65:1180-1185

Andersen AZ, Carvalho AL, Neves AR, Santos H, Kummer U, Olsen LF (2009) The metabolic $\mathrm{pH}$ response in Lactococcus lactis: an integrative experimental and modelling approach. Comput Biol Chem 33:71-83
Aso Y, Hashimoto A, Ohara H (2019) Engineering Lactococcus lactis for D-lactic acid production from starch. Curr Microbiol 76:1186-1192

Axelsson L (2004) Lactic acid bacteria: classification and physiology. In: Salminen S, Von Wright A (eds) Lactic acid bacteria: microbiological and functional aspects, 3rd edn. Marcel Dekker, New York, Basle, pp 1-72

Bintsis T (2018) Lactic acid bacteria as starter cultures: an update in their metabolism and genetics. AIMS Microbiol 4:665-684

Cameron DC, Cooney LC (1986) A novel fermentation: the production of $(R)$ 1,2-propanediol and acetol by Clostridium thermosaccharolyticum. Bio/ technol 4:651-654

Carvaiho AL, Turner DL, Fonseca LL, Solopova A, Catarino T, Kuipers OP, Voit EO, Neves AR, Santos H (2013) Metabolic and transcriptional analysis of acid stress Lactococcus lactis, with a focus on the kinetics of lactic acid pools. PLOS ONE 8:e68470

Elferink SJWHO, Krooneman J, Gottschal JC, Spoelstra SF, Faber F, Driehuis F (2001) Anaerobic conversion of lactic acid to acetic acid and 1,2-propanediol by Lactobacillus buchneri. Appl Environ Microbiol 67:125-132

Eş I, Mousavi Khaneghah A, Barba FJ, Saraiva JA, Sant'Ana AS, Hashemi SMB (2018) Recent advancements in lactic acid production-a review. Food Res Int 107:763-770

Gao C, Jiang T, Dou P, Ma C, Li L, Kong J, Xu P (2012) NAD-indipendent L-lactate dehydrogenase is required for L-lactate utilization in Pseudomonas stutzeri. PLoS ONE 7(5):e36519

Ghaffer T, Irshad M, Anwar Z, Aqil T, Zulifqar Z, Tariq A, Kamran M, Ehasan N, Mehmood S (2014) Recent trends in lactic acid biotechnology: a brief review on production to purification. J Rad Res Appl Sci 7:222-229

Gibson GD, Young L, Chuang YR, Venter CJ, Clyde AH III, Hamilton OS (2009) Enzymatic assembly of DNA molecules up to several hundred kilobases. Nat Methods 6:343-345

Huang H, Gong SC, Tsao TG (2002) Production of 1,3-propanediol by Klebsiella pneumonia. Appl Biochem Biotechnol 98-100:687-698

Huang J, Wu Y, Wu W, Zhang Y, Liu D, Chen Z (2017) Cofactor recycling for coproduction of 1,3-propanediol and glutamate by metabolically engineered Corynebacterium glutamicum. Sci Rep 7:422-446

Krooneman J, Faber F, Alderkamp AC, Quder Elferink SJHW, Driehuis F, Cleenwerck I (2002) Lactobacillus diolivorans sp. nov. a 1,2-propaneioldegrading bacterium isolated from aerobically stable maize silage. Int J Syst Evol Microbiol 52:639-646

Kuipers OP, de Ruyter PG, Kleerebezem M, de Vos WM (1998) Quorum sensingcontrolled gene expression in lactic acid bacteria. J Biotechnol 64:15-21

Lee HJ, Lama S, Kim RJ, Park HS (2018) Production of 1,3-propanediol from glucose by recombinant Escherichia coli BL21 (DE3). Biotech Bioproc Eng 23:250-258

Liang Q, Zhang H, Li S, Qi Q (2011) Construction of stress-induced metabolic pathway from glucose to 1,3-propanediol in Escherichia coli. App Microbiol Biotechnol 89:57-62

Lin J, Zhang Y, Xu D, Xiang G, Jia Z, Gong H (2016) Deletion of poxB, pta, and ackA improves 1,3-propanediol production Klebsiella pneumonia. Appl Microbiol Biotechnol 78:918-926

Linares DM, Kok J, Poolman B (2010) Genome sequence of Lactococcus lactis MG1363 (revised) NZ9000 and comparative physiological studies. J Bacteriol 192:5806-5812

Nakamura CE, Whited GM (2003) Metabolic engineering for the microbial production of 1,3-propanediol. Curr Opin Biotechnol 60:191-198

Neves AR, Ramos A, Costa H, Swam IIV, Hugenholtz J, Kleerebezem M, Vos WD, Santos H (2002) Effect of different NADH oxidase levels on glucose metabolism by Lactococcus lactis: kinetics of intracellular metabolite pools determined by in vivo nuclear magnetic resonance. Appl Environ Microbiol 68(12):6332-6342

Niu W, Guo J (2015) Stereospecific microbial conversion of lactic acid into 1,2-propanediol. ACS Synth Biol 4:378-382

Niu W, Kramer L, Mueller J, Liu K, Guo J (2019) Metabolic engineering of Escherichia coli for the de novo stereospecific biosynthesis of 1,2-propanediol through lactic acid. Metab Eng Commun 7:e00082

Palmfeldt J, Paese M, Hägerdal BH, van Niel EWJ (2004) The pool of ADP and ATP regulates anaerobic product formation in resting cells of Lactococcus lactis. Appl Environ Microbiol 70(9):5477-5484

Papagianni M, Avramidis N (2011) Lactococcus lactis as a cell factory: a twofold increase in phophofructokinase acitivity results in a proportional increase in specific lactate formation. Enzyme Microb Technol 49:197-202 
Papagianni M, Avramidis N, Filiousis G (2007) Glycolysis and the regulation of glucose transport in Lactococcus lactis spp. lactis in batch and fed-batch culture. Microb Cell Fact 6:16

Puvendran K, Jayaraman G (2019) Enhancement of acetyl-CoA by acetate co-utilization in recombinant Lactococcus lactis cultures enables the production of high molecular weight hyaluronic acid. Appl Microbiol Biotechnol 103:6989-7001

Ramos A, Boels IC, de Vos WM, Santos H (2001) Relationship between glycolysis and exopolysaccharide biosynthesis in Lactococcus lactis. Appl Environ Microbiol 67:33-41

Rahman MAA, Tashiro Y, Sonomoto K (2013) Recent advances in lactic acid production by microbial fermentation processes. Biotechnol Adv 31:877-902

Sato R, Tanaka T, Ohara H, Aso Y (2020) Engineering Escherichia coli for direct production of 1,2-propanediol and 1,3-propanediol from starch. Curr Microbiol 77:3704-3710

Sato R, Tanaka T, Ohara H, Aso Y (2021) Disruption of glpF gene encoding the glycerol facilitator improves 1,3-propanediol production from glucose via glycerol in Escherichia coli. Lett Appl Microbiol 72(1):68-73

Saxena RK, Anand P, Saran S, Isar J, Agarwal L (2010) Microbial production and applications of 1,2-propanediol. Indian J Microbiol 50(1) 2-11 10.1007/ s12088-010-0017-x

Tong TI, Liao HH, Cameron CD (1991) 1,3-propanediol production by Escherichia coli expressing genes from the Klebsiella pneumonia dha regulon. Appl Environ Microbiol 57:3541-3546
Usmani Z, Sharma M, Awasthi AK, Sivakumar N, LikkT, Pecoraro L, Thakur VK, Roberts D, Nebold J, Gupta VK (2021) Bioprocessing of waste biomass for sustainable product development and minimizing environmental impact. Biores Technol 322:1245-1248

van de Guchte M, Kok J, Venema G (1992) Gene expression in Lactococcus lactis. FEMS Microbiol Rev 8:73-92

Wang M, Wang G, Zhang T, Fan L, Tan T (2017) Multi-modular engineering of 1,3-propanediol biosynthesis system in Klebsiella pneumoniae from cosubstrate. Appl Microbiol Biotechnol 101:647-657

Wegmann U, Motherway MOC, Zomer A, Buist G, Shearman C, Canchaya C, Ventura M, Goesmann A, Gasson MJ, Kuripers OP, Sinderen DV, Kok J

(2007) Complete sequence of the prototype lactic acid bacterium Lactococcus lactis subsp. cremoris MG1363. J Bacteriol 189:3256-3270

Zhao C, Zhao Q, Yin L, Zhang Y (2017) Engeneering redox homeostasis to develop efficient alchohol-producing mirobial cell factories. Microb Cell Fact 16:115

\section{Publisher's Note}

Springer Nature remains neutral with regard to jurisdictional claims in published maps and institutional affiliations.

\section{Submit your manuscript to a SpringerOpen ${ }^{\circ}$ journal and benefit from:}

- Convenient online submission

- Rigorous peer review

- Open access: articles freely available online

- High visibility within the field

- Retaining the copyright to your article

Submit your next manuscript at $\boldsymbol{\nabla}$ springeropen.com 